\title{
APLIKASI AUGMENTED REALITY UNTUK PENGENALAN PERANGKAT JARINGAN KOMPUTER BERBASIS ANDROID SEBAGAI MEDIA PEMBELAJARAN INTERAKTIF
}

\author{
Sigit Wasista $^{1}$, Setiawardhana ${ }^{2}$, Ahmad Yusuf Ardiansyah ${ }^{3}$ \\ Program Studi D4 Teknik Komputer \\ Departemen Informatika dan Komputer Politeknik Elektronika Negeri Surabaya \\ Kampus PENS, Jalan Raya ITS Sukolilo, Surabaya 60111 \\ wasista@pens.ac.id, : setia@pens.ac.id, yusufardian@ce.student.pens.ac.id
}

\begin{abstract}
Abstrak
Tujuan adanya diciptakannya aplikasi ini adalaha untuk memberikan solusi dari permasalahan tersebut, yaitu membuat aplikasi pembelajaran tentang pengenalan perangkat jaringan komputer beserta topologi jaringannya dengan menggunakan teknologi Augmented Reality, agar dapat memberikan nuansa baru dan dapat mengurangi rasa bosen dalam belajar. Aplikasi yang diberi nama "PengajAR" adalah teknologi yang dapat menvisualisasikan gambar 3 dimensi kedalam virtual reality (penglihatan virtual). Marker yang terdapat pada masing masing perangkat bergambar akan ditangkap oleh kamera mobile device yang kemudian diproses untuk menampilkan animasi 3D modeling pada layar secara realtime. PengajAR menyajikan pengetahuan tentang fungsi perangkat jaringan seperti Router, Hub, Lan Tester, Access Point, karakteristik topologi Star, Mesh, Ring, dan Bus, selain itu aplikasi PengajAR menyediakan fitur Kuis untuk latihan soal seputar materi dasar perangkat jaringan komputer, dan dilengkapi dengan fitur Minigame yang memberikan latihan cara merancang model jaringan kabel dan wireless, serta terdapat fitur setting nomor IP (Internet Protocol). Pengujian yang dilakukan adalah dengan menggunakan metode Study Field, didemonstrasikan langsung ke siswa SMK (end user) yang akan mencoba aplikasi ini, Para siswasiswi diberikan beberapa tugas untuk merancang jaringan, dan diakhir acara siswa-siswi diminta untuk mengisi kuisioner sebagai penilaian atas perangkat lunak yang telah mereka gunakan. Hasil luaran yang diharapkan dari kontribusi media pembelajaran ini adalah dapat membantu mereview materi sebesar $40 \%$ yang telah diajarkan oleh guru, serta membantu untuk memvisualisasikan cara kerja topologi jaringan komputer sebesar $45 \%$, dan secara keseluruhan aplikasi ini sangat sesuai dengan materi komputer dan jaringan.
\end{abstract}

Kata Kunci: Augmented Reality, Marker, Topologi Jaringan, Internet Protocol

\section{Latar Belakang}

Pada hakikatnya guru adalah tonggak dalam pendidikan. Strategi, metode, media hingga bahan ajar terus di uji cobakan untuk meningkatkan hal terbaik bagi para peserta didik. Namun hal yang terpenting adalah metode dan media yang digunakan dalam proses pembelajaran harus kreatif dan innovatif. Metode pembelajaran interaktif 
adalah suatu cara atau teknik pembelajaran yang digunakan guru pada saat menyajikan bahan pelajaran dimana pemeran utama dalam menciptakan situasi yang interaktif, dan edukatif, dalam pembelajaran untuk menunjang tercapainya tujuan belajar. Selama ini penggunaan modul pembelajaran seperti buku paket TKJ (teori), LKS (Lembar Kerja Siswa), dan modul praktikum simulasi perancangan jaringan komputer dirasakan masih kurang variatif dalam pembelajaran di SMK khususnya jurusan TKJ (Teknik Komputer dan Jaringan). Oleh karena itu dibutuhkan sebuah media yang interaktif agar siswa dapat termotivasi dalam berfikir kreatif, akif dan edukatif. PengajAR menyajikan pengetahuan tentang fungsi perangkat jaringan

Penelitian sebelumnya yang telah dilakukan oleh Walesa Danto, Agung Toto Wibowo, Bedy Purnama [7] tentang analisa Metode Occlusion dan Interaksi dengan objek virtual secara real time menggunakan gerakan marker. Serta dijelaskan seputar operasi translasi dan rotasi untuk memudahkan dalam tracking marker terhadap kamera,

Penelitian sebelumnya yang telah

dilakukan oleh Danakorn Nincarean, Mohammad Bilal Ali, Noor Dayana Abdul Halim, Mohd Hishamuddin Abdul Rahman [8], Meneliti tentang cara potensi belajar yang menyenangkan dan interaktif bagi sebagian murid dalam dunia pendidikan. Dari hasil survey salah seorang peserta didik menyatakan bahwa augmented reality memberikan kontribusi belajar lebih menyenangkan, dan sarana yang tepat untuk mempelajari sejarah kota.

Penelitian sebelumnya yang telah dilakukan oleh Edmund $\mathrm{Ng}$ Giap Weng, Rehman Ullah Khan, Ahahren Ahmad Zaidi Adruce, Oon Yin Bee [9] dalam International Conference on Cognitive Science tentang tracking objek menggunakan kamera, serta bagaimana cara menentukan lokasi objek terhadap layar (screen).
Berangkat dari beberapa peneliti sebelumnya, peneliti bertujuan membuat aplikasi yang memiliki karakterisitik khususnya dibidang Jaringan Komputer tentang Pengenalan Perangkat Jaringan Komputer yang divisualisasikan dengan menggunakan teknologi Augemented Reality.

\section{Metode Perancangan dan Pembuatan Sistem Interaktif AR Jaringan Komputer}

Pembuatan sistem yaitu meliputi pembuatan AR kamera yang digunakan untuk mendeteksi, dan mengidetifikasi marker objek. Mesh Collider, dan Mesh Renderer komponen yang difungsikan sebagai Renderer Objek dan Animasi objek. Aplikasi PengajAR dibangun menggunakan game engine Unity 4.5 dan Blender 4.5, didukung dengan Android SDK serta Android SDK Platform-tools. Berikut adalah siklus cara kerja pembuatan perangkat lunak :

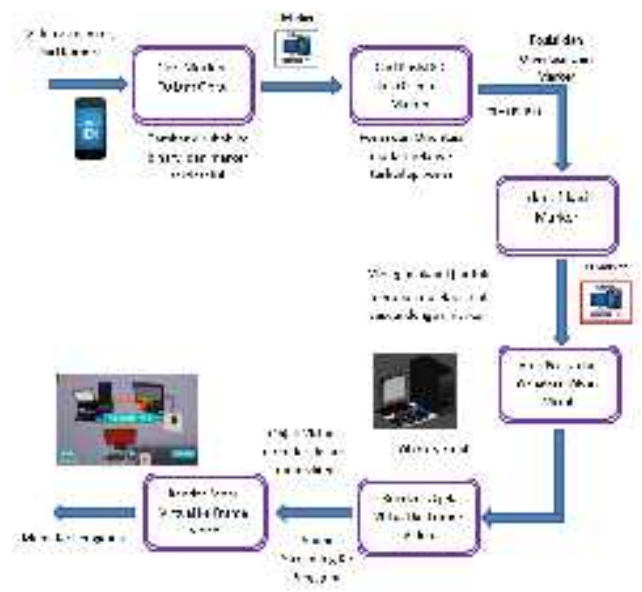

Gambar 2.1. Siklus Cara Kerja Perangkat Lunak

Dalam perancangan objek perangkat digunakan package marker yang di download dari Vuforia, AR camera, Objek 3D perangkat komputer, dan file pendukung 
lainnya seperti, Box Collider, Mesh Renderer, Text Mesh dll.

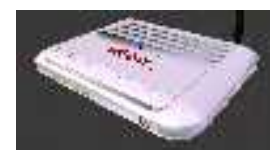

Gambar 2.2. Perancangan Objek Modem

Pembuatan objek dan perangkat pendukung seperti modem, Hub, Lan Tester, Router dll menggunakan aplikasi Blender. Komponen yang digunakan dalam pembuatan objek.

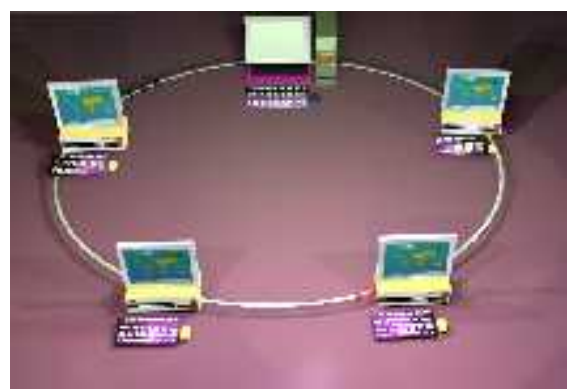

Gambar 2.3. Perancangan Topologi Jaringan

Perancangan Topologi Jaringan pada aplikasi ini digunakan untuk memberikan ilustrasi model dan karateristik dari setiap model topologi yang ada.

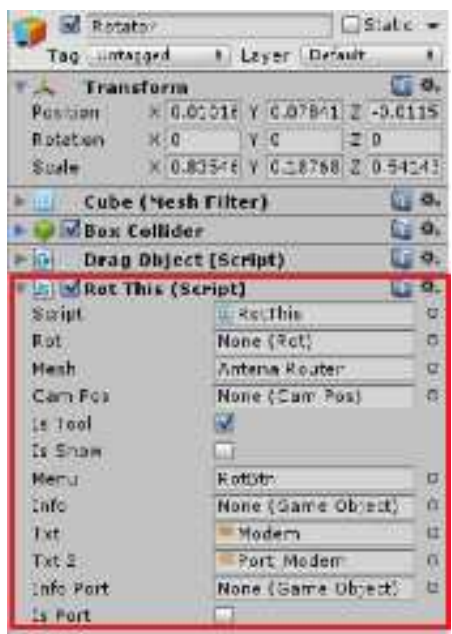

Gambar 2.4. Komponen Perangkat Jaringan
Dalam merancang perangkat jaringan komputer dibutuhkan komponen seperti Cube (Mesh Filter), Box Collider, Drag Object, dan Rot This. Semua komponen diintergrasikan dalam suatu GameObejct Rotator. Perancangan menggunakan tambahan texture.PNG. Texture berisi infromasi tentang fungsi perangkat, dan info port dari masing masing perangkat komputer.

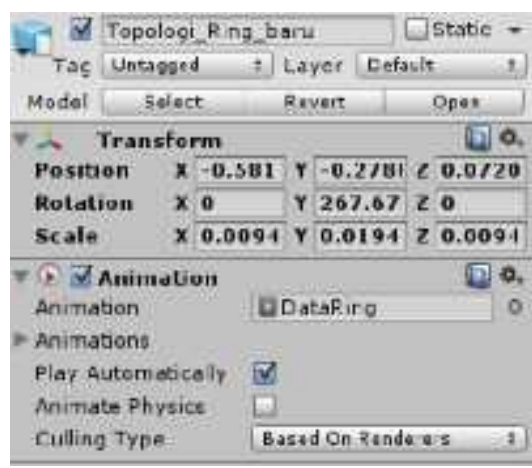

Gambar 2.5. Animate Physic

Desain arsitektur aplikasi dilakukan perancangan struktur sebuah perangkat lunak. Perancangan ini meliputi komponen perangkat lunak secara global seperti User Interface, komponen objek 3D dan animasi topologi jaringan, Serta respon UI terhadap interaksi pengguna.

\subsection{Desain Alur Kerja}

Desain alur kerja atau lebih dikenal dengan istilah workflow design merupakan pembuatan skenario bagaimana sistem aplikasi dijalankan oleh pengguna. Proses dari fitur - fitur perangkat lunak dijelaskan dan dianalisa secara detail. Proses ini dapat membantu untuk melihat efisiensi dari pembuatan algoritma program. Secara garis besar alur kerja sistem adalah : 


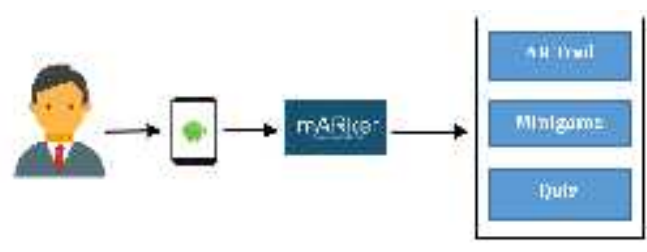

Gambar 2.6. Sistem Secara Global

Dengan urutan awal dari user membuka aplikasi AR dengan menggunakan perangkat Android (mobile device, tablet), kemudian user memilih tombol menu dan mengarahkan kamera pada perangkat Android ke Marker perangkat jaringan atau topologi jaringan, pada proses ini kamera Android akan mendeteksi marker secara otomatis dan akan ditampilkan animasi bergerak sesuai dengan tombol menu yang dipilih. Apabila user memilih menu kuis sistem akan menyediakan sepuluh pertanyaan dan empat buah jawaban a, b, c, d. dan Fitur selanjutnya yakni adalah minigame, dimana user dapat melakukan perancangan simulasi model jaringan kabel atau wireless dengan didukung konfigurasi IP yang tepat.

\subsection{Desain Objek dan Animasi Topologi}

Desain komponen perangkat lunak yaitu perancangan semua komponen perangkat lunak secara spesifik yang meliputi komponen User Interface dan juga data yang ada di dalamnya.

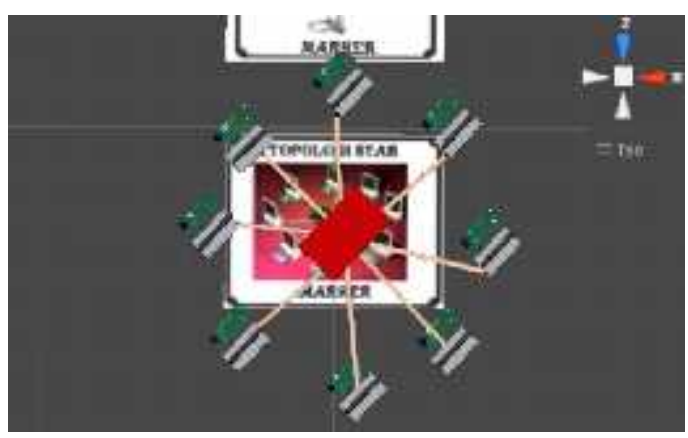

Gambar 2.7. Desain Topologi Star

Komponen ini dirancang dan dibuat untuk mendukung alur kerja di tahap sebelumnya. Desain komponen perangkat lunak dibagi menjadi dua bagian yaitu desain komponen GUI dan desain komponen data.

\section{Hasil Pembuatan Sistem Permainan}

Sistem yang telah dibuat terdiri splash screen, menu utama, sub menu, menu Kuis, Minigame, dan Animasi Connected. Ghrapical User Interface (GUI) merupakan media yang digunakan oleh pengguna dalam berinteraksi dengan perangkat lunak atau perangkat elektronik menggunakan gambar secara simbolik.

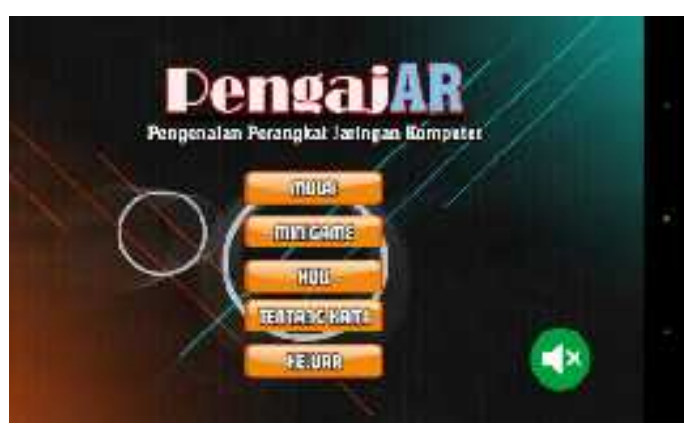

Gambar 3.1. Menu Utama

Hasil tampilan menu utama terdiri dari beberapa menu pilihan, seperti Mulai yang berisi tentang Pengenalan perangkat jaringan komputer beserta topologi, menu Minigame, dan Kuis. Komponen GUI bertujuan untuk meminimalisir penggunaan perintah secara tekstual menjadi simbolik untuk memudahkan pengguna.

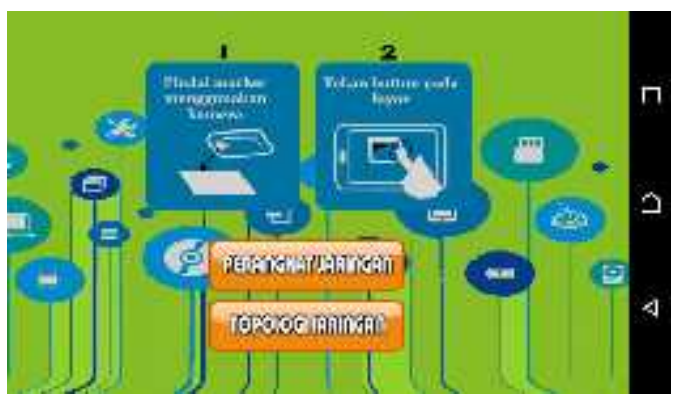

Gambar 3.2. Menu Mulai 
(AR Tool dan Topologi)

Hasil Menu Mulai user interface yang menyajikan user Bermain dengan perangkat jaringan komputer dan topologi dengan menggunakan Augmented Reality.

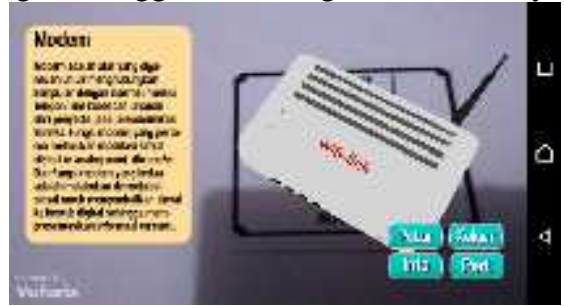

Gambar 3.3. AR Tool Modem

Hasil menampilkan perangkat dengan model 3D menyerupai perangkat aslinya. Terdapat 4 button yakni button putar, info, port dan keluar. Pada button Info dan Port menyajikan informasi tentang manfaat dan fitur pada perangkat Modem.

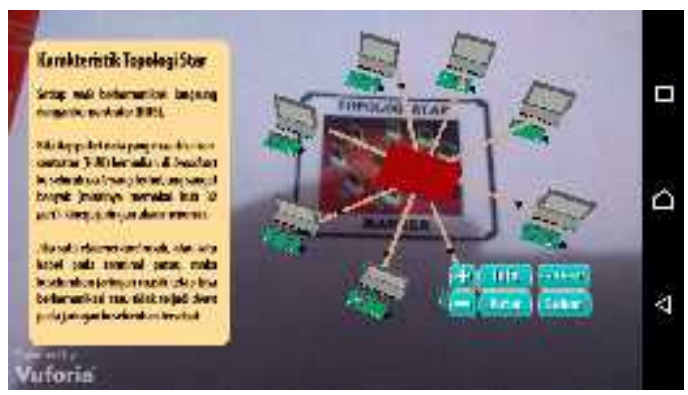

Gambar 3.4. AR Topologi Star

Hasil menampilkan AR Topologi model Star 3D. Menyajikan ilustrasi paket pengiriman data pada model topologi jaringan. Terdapat 6 button yakni button putar, info, port keluar. Karakteristik, kelebihan, dan kekurangan. Button yang ditampilkan berfungsi memberikan informasi pada user tentang manfaat dan fitur pada setiap topologi jaringan.

\subsection{Desain Komponen GUI (Kuis: Evaluasi Materi)}

Fitur Kuis pada aplikasi AR PengajAR berupa soal materi dasar jaringan komputer, kontennya disaijikan dalam bentuk dig 10 point.

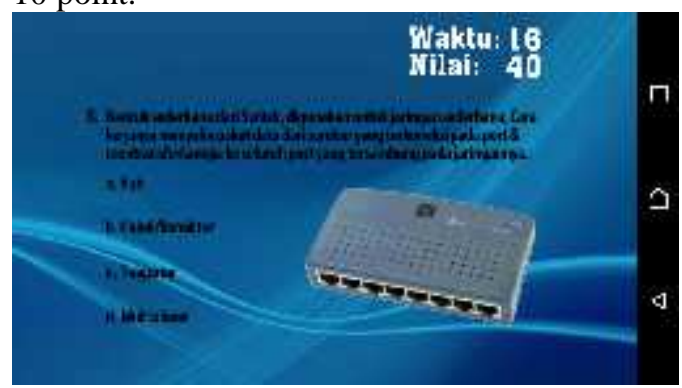

Gambar 3.5. Kuis Soal Komputer Dasar

Ditinjau dari bentuk penilaiannya model Kuis yang disajikan memberikan kriteria penilaian yang ditampilkan dalam bentuk kata dan nilai seperti Excellent jika nilai 100, Cool jika nilai 90, Good jika nilai 70-80, dan Bad jika nilai yang didapatkan kurang dari 60 .

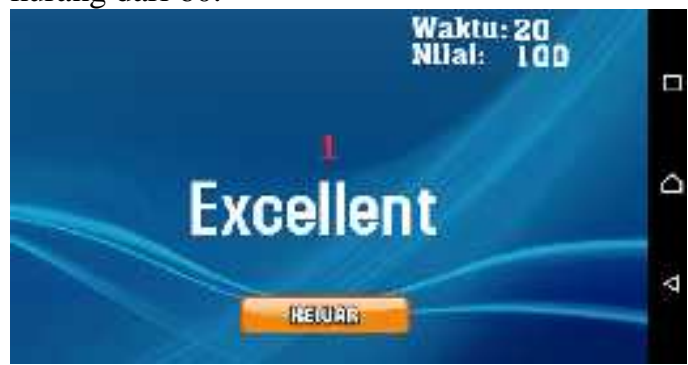

Gambar 3.6. Kriteria Penilaian Kuis

Fitur Kuis yang disajikan memberikan hasil evaluasii belajar pada siswa, materi pengenalan perangkat jaringan komputer beserta topologi, konfigurasi IP address akan mengingatkan pada materi yang sudah diajarkan oleh guru.

\subsection{Desain Minigame}

Fitur aplikasi PengajAR yang kedua adalah fitur minigame, fitur ini menyajikan simulasi cara merancang model jaringan 
kabel dan jaringan wireless skala kecil yang dikemas dalam bentuk permainan.

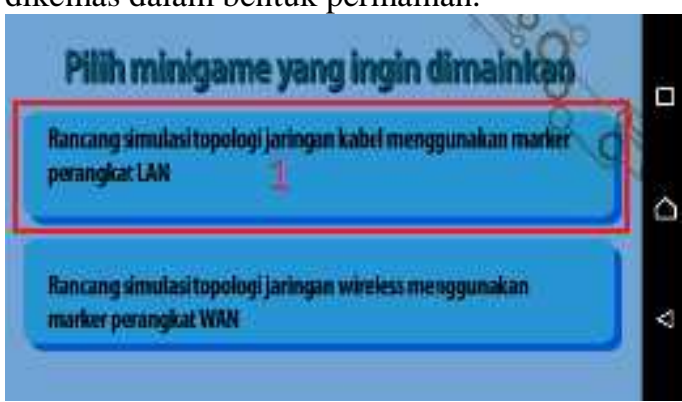

Gambar 3.7. Menu Minigame

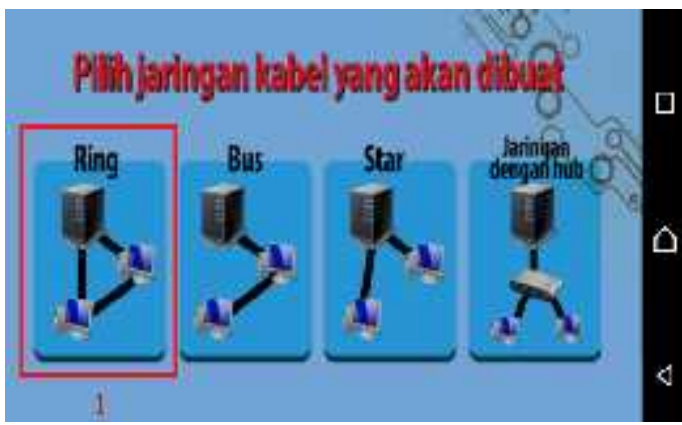

Gambar 3.8. Menu Jaringan Kabel (Minigame)

Pada model jaringan atau yang lebih dikenal sebagai topologi jaringan, terdapat tiga tipe topologi jaringan yang pertama adalah topologi Ring, Bus, Star, dan menu optional penambahan perangkat hub dan modem. Berikut ini bagian-bagian dalam fitur minigame.

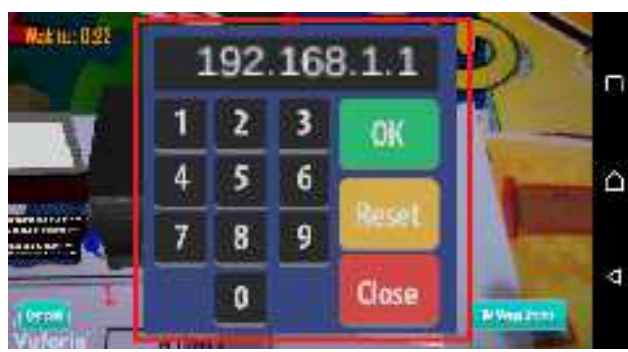

Gambar 3.9. Konfigurasi IP Kelas C Bagi Server
Konfigurasi ini dilakukan pada masing masing Objek seperti Server, Klient 1, dan Klient 2. Nomor IP disetting sesuai dengan intruksi yang ada pada screen cara bermaian.

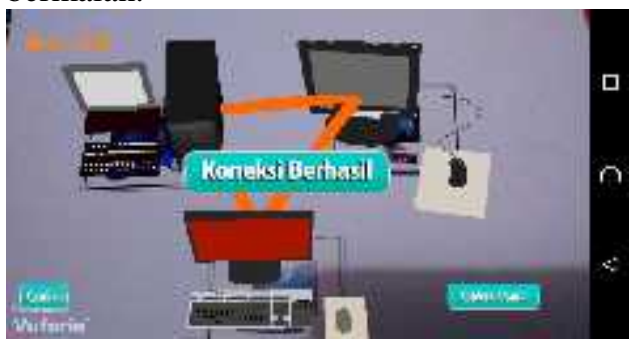

Gambar 3.10. Jaringan Kabel yang Berhasil Tersambung

Hasil diatas dapat muncul, dari beberapa tahapan, pertama user melakukan scan marker minigame, selanjutnya user malakukan setting IP sesuai dengan intruksi dan jika benar maka akan muncul animasi kabel yang tersambung.

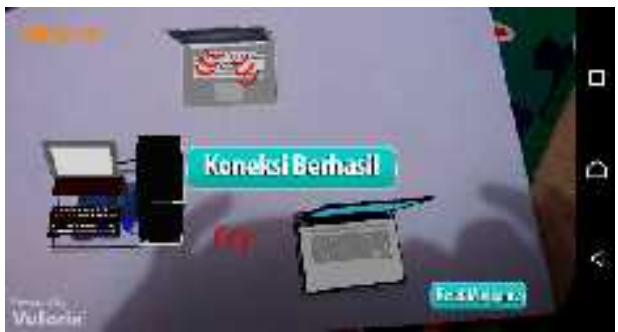

Gambar 3.11. Jaringan Wireless yang Berhasil Tersambung

\subsection{Hasil dan Analisa Pengujian Sistem Permainan}

Lingkungan uji coba dan spesifikasi minimum sistem sebagai berikut :

a. Perangkat Mobile (Hardware)

1. Sistem Operasi : Android 3.2

Honeycomb (API level 13)

2. Prosesor $: 800 \mathrm{MHz}$

3. RAM : $512 \mathrm{MB}$

4. Back Kamera : $2 \mathrm{MP}$

5. Layar : 4 Inchi

b. Perangkat Lunak (Software) 
1.Sistem Operasi $\quad$ : Windows $10-64$ bit

2.Software Build : Unity3D 4.5 64bit, AR Camera, Marker Package, Camtasia Recorder. Texture.png

\subsection{Pengujian Jarak Terhadap Marker}

Pengujian jarak terhadap marker dilakukan dengan tujuan untuk menganalisa performa dari aplikasi terhadapa marker terdapat beberapa merek HP android. Berikut merupakan hasil dari percobaan pengujian jarak dan kecepatan deteksi

Tabel 4.1. Pengujian Jarak

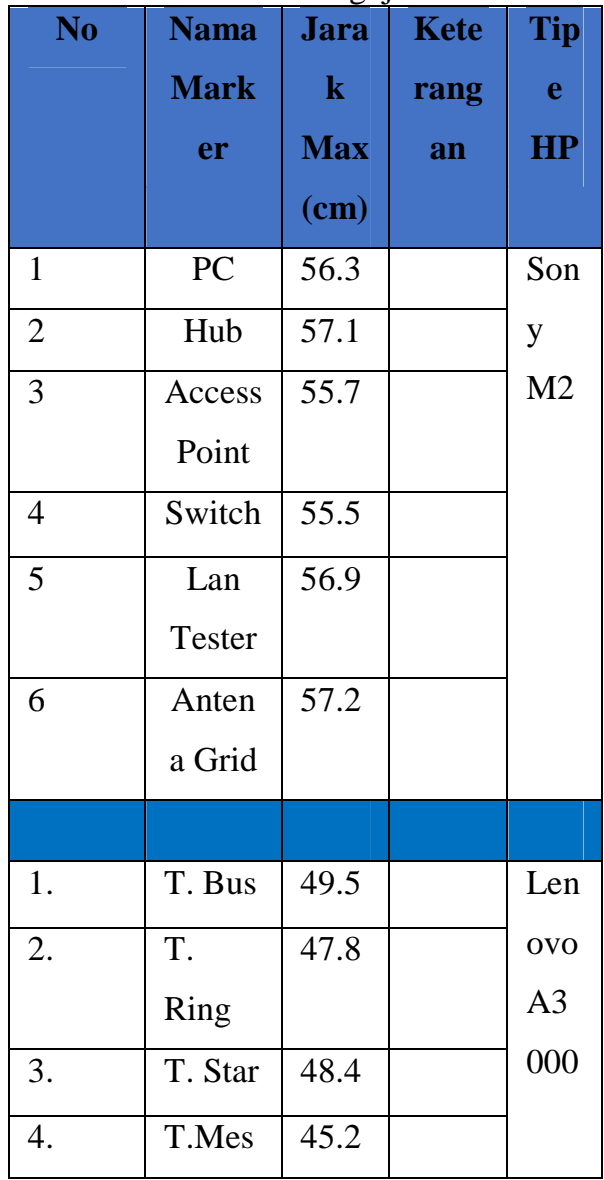

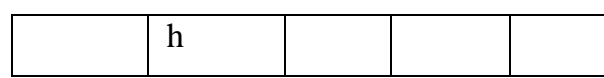

\subsection{Pengujian Sudut Terhadap Marker}

Pengujian sudut dilakukan dengan tujuan untuk menganalisa performa dari aplikasi terhadapa marker terdapat beberapa merek HP android. Berikut merupakan hasil dari percobaan presisi pengujian sudut terhadapt marker.

Tabel 4.2. Pengujian Sudut

\begin{tabular}{|c|c|c|c|c|}
\hline $\begin{array}{c}\text { Jenis } \\
\text { Marker }\end{array}$ & Tipe hp & $\begin{array}{c}\text { Nama } \\
\text { Marker }\end{array}$ & $\begin{array}{c}\text { Su } \\
\text { dut } \\
(0)\end{array}$ & $\begin{array}{c}\text { Ketera } \\
\text { ngan }\end{array}$ \\
\hline \multirow{10}{*}{$\begin{array}{l}\text { Marker } \\
\text { Tool }\end{array}$} & \multirow{10}{*}{$\begin{array}{l}\text { Sony } \\
\text { M2 }\end{array}$} & \multirow{5}{*}{$\begin{array}{l}\text { Lan } \\
\text { Tester }\end{array}$} & 90 & $\sqrt{ }$ \\
\hline & & & 70 & $\sqrt{ }$ \\
\hline & & & 60 & $\sqrt{ }$ \\
\hline & & & 50 & $\sqrt{ }$ \\
\hline & & & 30 & - \\
\hline & & \multirow{5}{*}{$\begin{array}{l}\text { Access } \\
\text { Point }\end{array}$} & 90 & $\sqrt{ }$ \\
\hline & & & 70 & $\sqrt{ }$ \\
\hline & & & 60 & $\sqrt{ }$ \\
\hline & & & 50 & $\sqrt{ }$ \\
\hline & & & 30 & - \\
\hline & & & & \\
\hline \multirow{10}{*}{$\begin{array}{l}\text { Marker } \\
\text { Topolo } \\
\text { gi }\end{array}$} & \multirow{10}{*}{$\begin{array}{c}\text { Himax } \\
\text { Pure III }\end{array}$} & \multirow[t]{5}{*}{ T. Bus } & 90 & $\sqrt{ }$ \\
\hline & & & 70 & $\sqrt{ }$ \\
\hline & & & 60 & $\sqrt{ }$ \\
\hline & & & 50 & - \\
\hline & & & 30 & - \\
\hline & & \multirow[t]{5}{*}{ T. Star } & 90 & $\sqrt{ }$ \\
\hline & & & 70 & $\sqrt{ }$ \\
\hline & & & 60 & $\sqrt{ }$ \\
\hline & & & 50 & - \\
\hline & & & 30 & - \\
\hline
\end{tabular}

\section{Kesimpulan}

Berdasarkan hasil pengujian dan analisa yang dilakukan maka dapat diambil kesimpulan :

1. Dengana adanya inovasi pengembangan media pembelajaran untuk pengenalan 
perangkat jaringan komputer dalam hal ini aplikasi PengajAR dapat menguramgi rasa jenuh dalam proses pembelajaran.

2. Aplikasi PengajAR dapat membantu me review materi TKJ terutama pada bagian merancangan jaringan komputer.

3. Aplikasi berjalan dengan baik pada perangkat mobile android khususnya device yang dibekali dengan GPU Qualcomm.

4. Hasil luaran yang diharapkan dari kontribusi media pembelajaran ini adalah dapat membantu mereview materi sebesar $40 \%$ yang telah diajarkan oleh guru, serta membantu untuk memvisualisasikan cara kerja topologi jaringan komputer sebesar $45 \%$, dan secara keseluruhan aplikasi ini sangat sesuai dengan materi komputer dan jaringan.

\section{Daftar Pustaka}

Danakorn Nincarean, Mohammad Bilal Ali, Noor Dayana Abdul Hakim, (2013). Mobile Augmented Reality: the Potential For Education. International Education Technology Conference, Diakses pada 22 Juni 2015 pukul 07.30.

Edmund Ng Giap Weng, Rehman Ullah Khan, Shahren Ahmad Zaidi Adruce, Oon Yin Bee (2013). Object Tracking From Natural in Mobile Augmented Reality. International Conference on Cognitive Science, Diakses pada 23 Juni 2015 pukul 05.30.

Hirzer Martin, (2008)," Marker Detection for Augmented Reality Applications", Inst For Computer Graphics and Vision Graz University of Technology Austria, Diakses 30 Juni 2015 pukul 22.10

Raviraj S. Patker, S. Pratap Singh, Swati V. Birje, (2013), Engineering "Marker Based Augmented Reality Using Android
OS”. International Jounal of Advanced Research in Computer Science and Softwere. Diakses 30 Juni 2015 pukul 22.30

Supriyanto, Modul Dikti (2013), Jaringan Dasar Untuk SMK / MAK Kelas X, Diakses 7 Agustus 2015 pukul 22.30

Walesa Danto, Agung Toto Wibowo, Bedy Purnama, SNASTIA - Institut Teknologi Bandung (2011), "Analisis Metode Occlusion Based Pada Augmented Reality Studi Kasus : Interaksi Dengan Objek Virtual Secara Real Time Menggunakan Gerakan Marker".

Yuan Tian, Yan Long, Dan Xia, Huang Xia, Jincheng Zhang (2015). Handling Occlusions in Augmented Reality Based on 3D Reconstruction Method. International Conference on Cognitive Science, Diakses pada 23 Juni 2015 pukul 05.45 . 